\title{
Regional trade-offs from multi-species maximum sustainable yield (MMSY) management options
}

\author{
Rudi Voss*, Martin F. Quaas, Jörn O. Schmidt, Julia Hoffmann \\ Department of Economics, University of Kiel, Wilhelm-Seelig-Platz 1, 24118 Kiel, Germany
}

ABSTRACT: The maximum sustainable yield (MSY) is, theoretically, the largest yield that can be taken from a single species' stock over an indefinite period. Formulation of strategic MSY management goals is, however, complicated by the need to move beyond biological single-species considerations. Interactions among species necessitate multispecies (MMSY) definitions, incorporating ecological, economic and social considerations. We developed an ecological-economic model of the Baltic Sea, simulating stock dynamics of interacting populations of cod Gadus morhua, herring Clupea harengus and sprat Sprattus sprattus. We investigated a set of different strategic management options. These likely, yet non-formalized experiments evaluate and illuminate alternative regional trade-offs. We computed multi-species maximum economic yield (MMEY) under certain ecological constraints, with profits as a performance indicator. An unconstrained profit-maximizing management strategy would lead to a highly profitable cod fishery in a cod-dominated ecosystem. Concurrent sprat stock size (and profits) would be low, falling below ecological precautionary reference points. Consideration of ecological constraints on minimum stock sizes leaves a range of strategies, including the change from a cod-dominated to a more clupeiddominated system. The regional distribution of profits depends on the management. Therefore, adjustment payments or other forms of compensation might be needed to achieve a concordant agreement on strategic multi-species management goals.

KEY WORDS: Equity $\cdot$ Baltic Sea $\cdot$ Distribution $\cdot$ Relative stability · Profits · Economic optimization · Bio-economic model

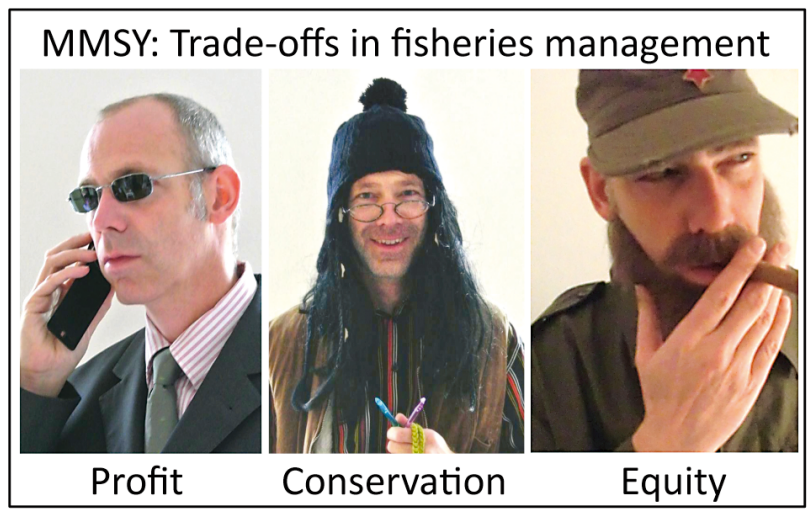

Managers must be able to wear different hats in order to achieve sustainability in multi-species fisheries.

Photos: Imme Schmidt

\section{INTRODUCTION}

Successful and commonly accepted fisheries management rules are a key to sustainability. Worldwide, approximately 500 million people are directly dependent on fisheries for earning their livelihood (FAO 2012). A growing world population, in combination with an increasing coastal population, is likely to further exacerbate problems linked to poor management of marine resources. Regulations are missing or are limping behind; partly because basic ecological and economic conditions for the relevant fishery are not understood. Even in Europe, fisheries management is still focused on single species, based on the natural sciences, but ignoring species interactions or any social and economic considerations. Consequently, in its latest evaluation of the European Common Fisheries Policy (CFP) the European Commission concluded that the CFP policy had failed and 
needed substantial revision (EC 2009). In the 2009 Green Paper on the reform of the CFP, the maximum sustainable yield (MSY) concept was included as a principle, accounting for the global imperative to manage fish stocks sustainably. Achieving this goal is complicated by the lack of a common interpretation of 'sustainability' and 'yield' and by the fact that achieving a theoretical long-term 'maximized' yield for one stock may detrimentally affect other stocks and may result in unwanted ecosystem, economic or social outcomes. Especially in systems with strong predator-prey links, either top down or bottom up, management decisions taken for one stock will inevitably influence the other stock(s). Rebuilding stocks of large predators like cod might negatively affect future profits from the corresponding prey-fish fishery, as the prey stocks will be depleted by the abundant predator. Different interpretations or prioritizations of 'yield' will therefore result in different long-term management goals, e.g. steering a system towards maximum yield in terms of biomass (usually prioritizing forage fish) is adverse to maximum yield in terms of profit (usually prioritizing large predatory fish). Unconstrained optimization for any given target might result in unacceptable situations, as defined by legally binding ecosystem indicators, e.g. the Good Environmental Status (GES) within the EU Marine Strategy Framework Directive (MSFD), or stock levels may fall below precautionary biomass levels. Therefore, the feasible 'space of possible solutions' might be narrower than originally perceived. However, even in a reduced decision space, decisions on trade-offs have to be explicitly made.

Current reforms of the CFP include new management measures, more regional structures and a more participatory and open process. However, some principles still seem to be 'carved in stone'. One principle which is not subject to discussion is the 'principle of relative stability'. According to this principle, the Baltic countries hold fixed shares of the quotas for cod Gadus morhua, herring Clupea harengus and sprat Sprattus sprattus. Therefore, the absolute catch amounts may differ between years depending on the stock status, but the percentage distribution of total allowable catches (TACs) to countries does not.

In this study we explored strategic management goals in a multi-species set-up and investigated the regional effects. We use the example of the Baltic Sea to show that inflexibility in the distribution of catch shares to countries, as constrained by the principle of relative stability, can lead to regional inequity in the distribution of future profits.
The fish community in the central Baltic Sea is dominated by cod, herring and sprat. The fishery mainly consists of single-species fisheries. However, the fish stocks are closely connected by strong ecological inter-connections between species (Köster \& Möllmann 2000), as cod preys on both herring and sprat (Lewy \& Vinther 2004). Thus, fluctuations in the size of the cod stock are related to considerable changes in natural mortality rates of sprat and juvenile herring. Under optimal management, the cod fishery would be the most profitable fishery by far (Nieminen et al. 2012, Quaas et al. 2013). The combination of high fishing pressure and environment-driven low recruitment success led to a decrease of the cod spawning stock biomass (SSB) from almost 700000 to $100000 \mathrm{t}$ from 1983 to 1992 , increasing shortly thereafter, but reaching a record low level in 2005 (ICES 2012). This strong decrease in the cod stock and a concurrent increase in the sprat stock resulted in a change from a coddominated system to a sprat-dominated system. In recent years the eastern Baltic cod recovered, like a number of other Northeast Atlantic stocks (Fernandes \& Cook 2013), to a spawning stock biomass of $>200000 \mathrm{t}$ in 2011 (ICES 2012). The recovery was due to a combination of improved recruitment and the implementation of a cod long-term management plan in 2006 (EC 2007). This plan was aimed at rebuilding the full reproductive capacity of the stock and resulted in better compliance and a substantially reduced fishing mortality $(F=0.3)$. A major difference compared to the previous management strategy is that inter-annual changes in TAC, both in terms of reductions and increases, are limited to a maximum of $15 \%$.

In June 2011, the European Commission and its member states agreed that the Baltic cod plan should be replaced by a Baltic multi-species management plan that would account for major species interactions. The Baltic Regional Advisory Council (RAC) also expressed support for such an approach. Accordingly, a number of expert groups were initiated, dealing e.g. with defining the methods of multispecies stock assessment (see Rindorf et al. 2013 for an overview). The scientific basis is formed by earlier multi-species works (Gislason 1999) showing that single- and multi-species reference points are different and that it is impossible to define a 'safe' level of biomass without taking changes in species interactions into account. The inclusion of first-order interactions is needed for medium-term management purposes (Collie \& Gislason 2001). In the case of the Baltic Sea this applies to predation mortality induced by the cod stock. Socio-economic considerations are often neglected in the terms of reference for the 
expert groups and are only treated in subsequent analysis. We think that this needs to be changed, as useful management targets can only be achieved by including more detailed socio-economic analysis of the fisheries (Gislason 1999).

Using 2006 as our base year (i.e. the year of adoption of the cod management plan), we undertake model experiments to investigate 4 hypothetical long-term management goals and their outcome in terms of ecology (stock sizes), economy (total profits) and social aspects (regional distribution of profits): (1) an unconstrained economic optimization (maximizing profits) of the 3 species system, (2) optimization of the cod fishery's present value, while respecting a precautionary biomass level of sprat, (3) optimization of the sprat fishery, while maintaining a precautionary biomass level of cod and (4) a simulation of the current cod management plan. We show that a change back to a cod-dominated system is economically highly profitable as an aggregate, but not all countries would actually benefit from this change in an equal way. Therefore, compensation might be needed to avoid inequity.

We developed and applied a combined 3-species, age-structured ecological-economic model, which takes cod predation on 2 clupeid species into account. We used 4 scenarios (Table 1) to investigate the distribution of country-specific future profits.

\section{MATERIALS AND METHODS}

\section{Ecological-economic modeling}

Our model is an extension of the single-species age-structured fishery model of Tahvonen (2009) and Tahvonen et al. (2013), similar in scope to that of Nie-

Table 1. Management Scenarios 1 to 4 , using different sets of input or optimized fishing mortalities $(F)$. SSB: spawningstock biomass

\begin{tabular}{|ll|}
\hline Scenario & \multicolumn{1}{c|}{ Objective } \\
\hline 1 & $\begin{array}{l}\text { Unconstrained economic optimization } \\
\text { Optimization for profits from cod fishery, while } \\
\text { respecting a precautionary SSB }\left(B_{\mathrm{PA}}\right) \text { of } \\
570000 \text { t of sprat (ICES 2013) } \\
3\end{array}$ \\
$\begin{array}{l}\text { Optimization for profits from sprat fishery, } \\
\text { while respecting a cod } B_{\mathrm{PA}} \text { of } 88000 \text { t (ICES } \\
\text { 2013) } \\
\text { Simulation of the agreed long-term manage- } \\
\text { ment plan for cod and subsequent optimization } \\
\text { for clupeids }\end{array}$ \\
\hline
\end{tabular}

minen et al. (2012). We use the subscript $i \in\{\mathrm{C}, \mathrm{S}, \mathrm{H}\}$ for the $\operatorname{cod}(\mathrm{C})$, sprat $(\mathrm{S})$ and herring $(\mathrm{H})$ fisheries. The fishing profit for the cod fishery in year $t$ is:

$$
\pi_{\mathrm{C}}=\sum_{s=1}^{8} p_{\mathrm{C}}(s) w_{\mathrm{C}}(s)\left\{1-\mathrm{e}^{\left(-F_{\mathrm{C}}(t)\right)}\right\} q_{\mathrm{C}}(s) x_{\mathrm{C}}(s, t)-C_{\mathrm{C}} F_{\mathrm{C}}(t)
$$

Here we use $x_{C}(s, t)$ to denote stock numbers of age $s$ in year $t, p_{\mathrm{C}}(s)$ for age-specific prices, $w_{\mathrm{C}}(s)$ for agespecific weights and $q_{\mathrm{C}}(s)$ for age-specific relative catchabilities. Instantaneous fishing mortality is $F_{\mathrm{C}}(t)$, and the cost function is of the Spence (1974) type, where $C_{\mathrm{C}}$ is a cost parameter (as in Quaas et al. 2012). Sprat and herring $i=\mathrm{S}, \mathrm{H}$ are modeled as schooling fisheries (Tahvonen et al. 2013), with profits:

$$
\pi_{i}=\left(p_{i}-c_{i}\right) \sum_{s=1}^{8} w_{i}(s)\left\{1-\mathrm{e}^{\left(-F_{i}(t)\right)}\right\} q_{i}(s) X_{i}(s, t)
$$

where $p_{i}$ is the market price (which is assumed to be independent of age) and $C_{i}$ is the constant marginal cost of harvest. For each fishery $i=\mathrm{S}, \mathrm{H}, \mathrm{C}$ we consider a representative fisherman's intertemporal utility from fishing income:

$$
V_{i}=\sum_{t=0}^{\infty} \rho^{t} \frac{\pi_{i}^{1-\eta}}{1-\eta}
$$

where $\rho$ is the discount factor and $\eta$ is the representative fisherman's aversion against inter-annual income fluctuations.

The higher $\eta$ is, the more a constant income stream over time is preferred. Such a desire for relative constancy is reflected in several management plans for European fish stocks (e.g. Baltic cod; EC 2007), which have been agreed upon by a broad range of stakeholders, including fishermen. It is expressed, for example, as a requirement that TACs shall not change by more than a certain percentage between 2 subsequent years ( $15 \%$ in the case of Baltic cod).

The objective is to maximize a weighted sum of the intertemporal utilities $\left(E_{(t)}\right)$ of the representative fishermen of all 3 fisheries:

$$
\max _{E_{\mathrm{C}}(t), E_{\mathrm{S}}(t), E_{\mathrm{H}}(t)}\left\{\lambda_{\mathrm{C}} V_{\mathrm{C}}+\lambda_{\mathrm{S}} V_{\mathrm{S}}+\lambda_{\mathrm{H}} V_{\mathrm{H}}\right\}
$$

This model set-up allows changing the weights $\lambda_{i}>0$ to model different strategic management goals or constraints. In the case of unconstrained economic optimization we take $\lambda_{\mathrm{C}}=\lambda_{\mathrm{H}}=\lambda_{\mathrm{S}}=1$, which means that all 3 fisheries have equal weight in the management optimization. Fishing mortalities may not be negative, i.e. $F_{i}(t) \geq 0$ in all cases. The age-structured multi-species population dynamics are described as follows. SSB of species $i$ in year $t$ are given by: 


$$
\operatorname{ssb}_{i}(t)=\sum_{s=1}^{8} w_{i}(s) \gamma_{i}(s) X_{i}(s, t)
$$

where $\gamma_{i}(s)$ is used to denote age-specific maturities. Population dynamics of the stock of species $i$ are given by:

$$
\begin{aligned}
& X_{i}(s, t+1)=\varphi_{i} \operatorname{ssb}_{i}(t) \mathrm{e}^{\left[-\beta_{i} \operatorname{ssb}_{i}(t)\right]} \\
& \text { for } s=1 \\
& x_{i}(s, t+1)=\alpha_{i}(s-1)\left(1-q_{i}(s)\left\{1-\mathrm{e}^{\left[-F_{i}(t)\right]}\right\}\right) x_{i}(s-1, t) \quad \text { for } s=2, \ldots, 7 \\
& x_{i}(s, t+1)=\alpha_{i}(7)\left(1-q_{i}(s)\left\{1-\mathrm{e}^{\left[-F_{i}(t)\right]}\right\}\right) x_{i}(7, t)+\alpha_{i}(8) \\
& \left(1-q_{i}(8)\left\{1-\mathrm{e}^{\left[-F_{i}(t)\right]}\right\}\right) X_{i}(8, t) \\
& \text { for } s=8
\end{aligned}
$$

This formulation implies that fishing and natural mortality are sequential, and was chosen as it is standard in resource dynamics literature (Tahvonen 2009). Changing the model to address fishing and natural mortality as competitive causes of death would slightly affect cost and catch, but not population dynamics.

For cod and herring we assume stock-recruitment functions of the Ricker (1954) type; for sprat we assume a Beverton-Holt type (Beverton \& Holt 1957). Age-specific survival rates are:

$$
\begin{array}{lc}
\alpha_{\mathrm{C}}(s)=\mathrm{e}^{\left(-M_{\mathrm{C}}(s)\right)} & \text { for cod } \\
\alpha_{\mathrm{S}}(s, t)=\mathrm{e}^{\left(-M_{\mathrm{S} 1}(s)-M_{\mathrm{S} 2}(s) \mathrm{ssb}_{\mathrm{C}}\right)} & \text { for sprat } \\
\alpha_{\mathrm{H}}(s, t)=\mathrm{e}^{\left(-M_{\mathrm{H} 1}(s)-M_{\mathrm{H} 2}(s) \operatorname{ssb}_{\mathrm{C}}\right)} & \text { for herring }
\end{array}
$$

which are constant for cod. Residual $\left(M_{i 1}\right)$ and predation $\left(M_{i 2}\right)$ mortality estimates for the different age classes of herring and sprat are based on regression analysis, using SMS (Lewy \& Vinther 2004) output on mortality for different stock sizes of cod. Predation mortality is almost linearly dependent on the cod stock biomass for a wide range of stock states (Tahvonen et al. 2013). This shortcut in the calculation of $M_{i 2}$ values was used to reduce model complexity and implies a dependency of predation mortality on both predator and prey abundance.

\section{Data and estimation of model parameters}

Age-specific weights $w_{i}(s)$ and maturities $\lambda_{i}(s)$ were taken from the ICES (2012) assessment reports for the 3 stocks, using the mean values from 2002 to 2006.

Age-specific catchabilities were estimated based on mean age-specific fishing mortalities for the years 2002 to 2006, as reported in ICES (2012), with $q_{\mathrm{A}}=1$ for the age class with the highest mortality by normalization. In the case of reaching $q_{\mathrm{A}}=1$ for an age class $<8$, it was kept constant for the older age classes, as it is meant to reflect mesh-size selection (Table 2).

Natural mortalities for the herring and sprat age classes were calculated dependent on the size of the cod stock. Estimates are based on a stochastic multispecies model (SMS: Lewy \& Vinther 2004) and are reported in Table 3 . The parameters for the stockrecruitment functions are given in Table 4 .

For cod we used age-specific European reference prices, which are the lowest prices at which imports of cod of specific weight classes, sprat, or herring into the European Union are allowed (EC 1999, 2009), see Table 5. The cost parameter for cod is $C_{C}$ = 55.2 million euros (Quaas et al. 2012). To estimate prices and cost parameters for sprat, we used price data and data on variable fishing costs for the Swedish (years 2002 to 2008) and Polish (years 2005 to 2008) pelagic trawler and seiner fleets from STECF (2011), which led to $p_{\mathrm{S}}$ euros $\mathrm{kg}^{-1}$ for the price and $c_{\mathrm{S}}$ euros $\mathrm{kg}^{-1}$ for the cost parameter. Similarly, for herring, we used STECF (2011) data for the Danish, Estonian, Finnish, Polish and Swedish

\begin{tabular}{|c|c|c|c|c|c|c|c|c|c|c|c|c|}
\hline \multirow{2}{*}{$\begin{array}{l}\text { Age } \\
\text { class }\end{array}$} & \multicolumn{3}{|c|}{ Numbers in 2006 (millions) } & \multicolumn{3}{|c|}{ Maturity } & \multicolumn{3}{|c|}{ Weight (g) } & \multicolumn{3}{|c|}{ Catchability } \\
\hline & $\mathrm{C}$ & $\mathrm{H}$ & $\mathrm{S}$ & $\mathrm{C}$ & $\mathrm{H}$ & $\mathrm{S}$ & $\mathrm{C}$ & $\mathrm{H}$ & $\mathrm{S}$ & $\mathrm{C}$ & $\mathrm{H}$ & $\mathrm{S}$ \\
\hline 1 & 196.555 & 11597 & 60816 & 0 & 0 & 0.17 & 80 & 11 & 52 & 0 & 0.28 & 0.27 \\
\hline 2 & 131.041 & 5123 & 23884 & 0.13 & 0.7 & 0.93 & 179 & 20 & 84 & 0.11 & 0.44 & 0.49 \\
\hline 3 & 122.411 & 5519 & 60692 & 0.36 & 0.9 & 1 & 511 & 25 & 96 & 0.42 & 0.66 & 0.79 \\
\hline 4 & 52.298 & 5919 & 19240 & 0.83 & 1 & 1 & 838 & 31 & 105 & 0.81 & 0.82 & 0.85 \\
\hline 5 & 15.187 & 1713 & 3179 & 0.94 & 1 & 1 & 1204 & 37 & 111 & 1 & 0.97 & 1 \\
\hline 6 & 3.546 & 1105 & 1519 & 0.96 & 1 & 1 & 1796 & 43 & 113 & 1 & 0.96 & 1 \\
\hline 7 & 0.714 & 830 & 1510 & 0.96 & 1 & 1 & 2596 & 48 & 111 & 1 & 1 & 1 \\
\hline 8 & 0.383 & 789 & 1959 & 0.98 & 1 & 1 & 4068 & 53 & 113 & 1 & 1 & 1 \\
\hline
\end{tabular}
trawler and seiner fleets (years 2002 to 2008), which gave estimates of $p_{\mathrm{H}}$ euros $\mathrm{kg}^{-1}$ for the price and $c_{\mathrm{H}}$ euros $\mathrm{kg}^{-1}$ for the cost parameter. For the representative fisherman's aversion to inter-annual income fluctuations, we assumed $\eta=0.25$. The discount rate was set at 0 and $5 \%$, respectively.

Table 2. Gadus morhua (C), Clupea harengus (H), Sprattus sprattus (S). Parameters used in the ecological-economic model. Values for maturity, weight and catchability are from the ICES (2012) standard assessment, using mean values from 2002 to 2006; numbers at age (corrected for spawning time) are from ICES (2012) for 2006 
Table 3. Gadus morhua (C), Clupea harengus (H), Sprattus sprattus (S). Natural mortality estimates used in ecological-economic modeling. Residual and predation mortality estimates in the multi-species (interaction) case are based on regression analysis, using stochastic multi-species output on mortality for different stock sizes of cod

\begin{tabular}{|c|c|c|c|c|c|c|c|c|c|}
\hline \multirow[b]{2}{*}{ Age class } & \multicolumn{3}{|c|}{ Mortality 'no interaction' } & \multicolumn{3}{|c|}{ Residual mortality $\left(M_{1}\right)$} & \multicolumn{3}{|c|}{ Predation mortality $\left(M_{2}\right)$ coefficient } \\
\hline & C & $\mathrm{H}$ & $\mathrm{S}$ & $\mathrm{C}$ & $\mathrm{H}$ & $\mathrm{S}$ & $\mathrm{C}$ & $\mathrm{H}$ & $\mathrm{S}$ \\
\hline 1 & 0 & 0.2 & 0.2 & 0 & 0.1702028 & 0.1317657 & - & $3.324 \times 10^{-4}$ & $8.740 \times 10^{-4}$ \\
\hline 2 & 0.2 & 0.2 & 0.2 & 0.2 & 0.1727799 & 0.1366770 & - & $2.312 \times 10^{-4}$ & $7.076 \times 10^{-4}$ \\
\hline 3 & 0.2 & 0.2 & 0.2 & 0.2 & 0.1778390 & 0.1317657 & - & $0.448 \times 10^{-4}$ & $6.737 \times 10^{-4}$ \\
\hline 4 & 0.2 & 0.2 & 0.2 & 0.2 & 0.1878390 & 0.1317657 & - & $0.448 \times 10^{-4}$ & $6.737 \times 10^{-4}$ \\
\hline 5 & 0.2 & 0.2 & 0.2 & 0.2 & 0.1878390 & 0.1317657 & - & $0.448 \times 10^{-4}$ & $6.737 \times 10^{-4}$ \\
\hline 6 & 0.2 & 0.2 & 0.2 & 0.2 & 0.1878390 & 0.1317657 & - & $0.448 \times 10^{-4}$ & $6.737 \times 10^{-4}$ \\
\hline 7 & 0.2 & 0.2 & 0.2 & 0.2 & 0.1878390 & 0.1317657 & - & $0.448 \times 10^{-4}$ & $6.737 \times 10^{-4}$ \\
\hline 8 & 0.2 & 0.2 & 0.2 & 0.2 & 0.1878390 & 0.1317657 & - & $0.448 \times 10^{-4}$ & $6.737 \times 10^{-4}$ \\
\hline
\end{tabular}

\section{Numerical optimization}

To determine the optimal management, while paying regard to any given constraints in the management scenarios, we solved the optimization problem numerically. For this, the dynamic optimization was performed using the interior-point algorithm of the Knitro (Version 8.1) optimization software with Matlab (R2012b), as well as AMPL.

\section{Transition dynamics}

The transition path (i.e. short-term effects) towards the long-term management goal might be crucial for acceptance of that goal by the fisheries. Even if the long-term goal is accepted, the transition dynamics (e.g. fishing restrictions) might confront the fisheries with severe problems due to anticipated short-term income losses. In addition to the long-term steady state, we investigated the short-term (2006 to 2012) transition dynamics under each scenario. Yearly fishery-specific and total profits were calculated.

\section{Regional distribution of profits}

The distributional effects of the 4 management scenarios were calculated by simulating the interacting stock dynamics, associated species-specific catch and cost data and finally country-specific future profits. Country-specific quota allocation followed the relative stability principle. Overall annual profits were calculated as the sum of profits of all 3 fisheries. To illustrate the long-term distributional effect we chose the reference year 2030 , i.e. we chose a year after initial transition dynamics would have stabilized.

\section{RESULTS}

\section{Stock development scenarios}

Historic stock development shows a switch from a system dominated by cod Gadus morhua in the early 1980 s to a clupeid-dominated system beginning in the early 1990s (Möllmann et al. 2009; Fig. 1a). Up until the year 2006 no signs of cod recovery were observed.

In Management Scenario 1, we applied an unconstrained economic optimization of the multi-species fishery (Fig. 1b). This resulted in a fast rebuilding of the cod stock to ca. $700000 \mathrm{t}$ of SSB. The herring Clupea harengus stock increases in parallel to $>1$ million t of SSB, while the sprat Sprattus sprattus stock is reduced to $212000 \mathrm{t}$ of $\mathrm{SSB}$, due to the strong predatory impact of the large cod stock. This level of sprat SSB is well below the recently defined precautionary biomass limit for impaired recruitment (570000 t; ICES 2013).

In Scenario 2, the precautionary biomass level for sprat (sprat $B_{\mathrm{PA}}$ ) was used as a constraint. Keeping a minimum of $570000 \mathrm{t}$ sprat SSB reduces the optimal cod SSB to 329000 t. Optimal herring stock size reached almost 1.4 million $\mathrm{t}$ (Fig. 1c). Optimal fishing

Table 4. Parameters of stock-recruitment functions, obtained by either fitting a model to data from 1974 to 2011 as provided by ICES (2012) for herring, or functions by Quaas et al. (2012) for cod and Tahvonen et al.(2013) for sprat. Functions noted in parentheses

\begin{tabular}{|lcl|}
\hline & $\varphi_{i}$ & \multicolumn{1}{c|}{$\beta_{i}$} \\
\hline Cod (Ricker) & 1.7 & 0.00182 \\
Herring (Ricker) & 30.33 & 0.000469 \\
Sprat (Beverton-Holt) & 104.2 & 0.5032 \\
\hline
\end{tabular}


Table 5. Gadus morhua. Age-specific European reference prices for cod ((EC, 1999, 2009)

\begin{tabular}{|cc|}
\hline Age class & Price $(€ / \mathrm{kg})$ \\
\hline 1 & 0 \\
2 & 0.35 \\
3 & 0.35 \\
4 & 0.35 \\
5 & 0.477 \\
6 & 0.477 \\
7 & 0.636 \\
8 & 0.731 \\
\hline
\end{tabular}

mortality is considerably higher for all 3 species than in Scenario 1 (Table 6).

Setting a precautionary cod SSB $\left(\operatorname{cod} B_{\mathrm{PA}}\right)$ of $88000 \mathrm{t}$ (ICES 2013) as a constraint, while otherwise optimizing profits from the clupeid fishery (Scenario 3), increasingly emphasizes the role of herring and sprat (Fig. 1d). The precautionary stock size of cod could be maintained at a fishing mortality as high as $F=$ 0.9 ; the cod fishery would, however, be unprofitable (Table 6). SSB of herring and sprat peak at 1.5 million and 1.2 million $t$, respectively. This illustrates the broad range of strategic management options, while still accounting for ecological constraints.

The equilibrium stock sizes when simulating the cod management plan (Scenario 4) resemble the solution for the economically optimal solution (Fig. 1e). The cod stock increases slightly with corresponding smaller clupeid stock sizes as a result of intensified cod predation (Table 6). The target fishing mortality under the cod management plan $(F=0.3)$ is slightly lower than the steady-state fishing mortality under economically optimal management $(F=0.35)$.

The combined profits from all 3 fisheries are by far the highest if the cod stock is rebuilt (Table 6; Scenarios 1 and 4). The economically optimal management plan is only slightly better in terms of combined profits compared to the simulated cod management plan. (The difference in present-value terms is a bit larger because of the faster transition to an optimal steady state under optimal management.) According to our model, the cod fishery would not be profitable (zero profits) in Scenario 3, i.e. if the fishing mortality of
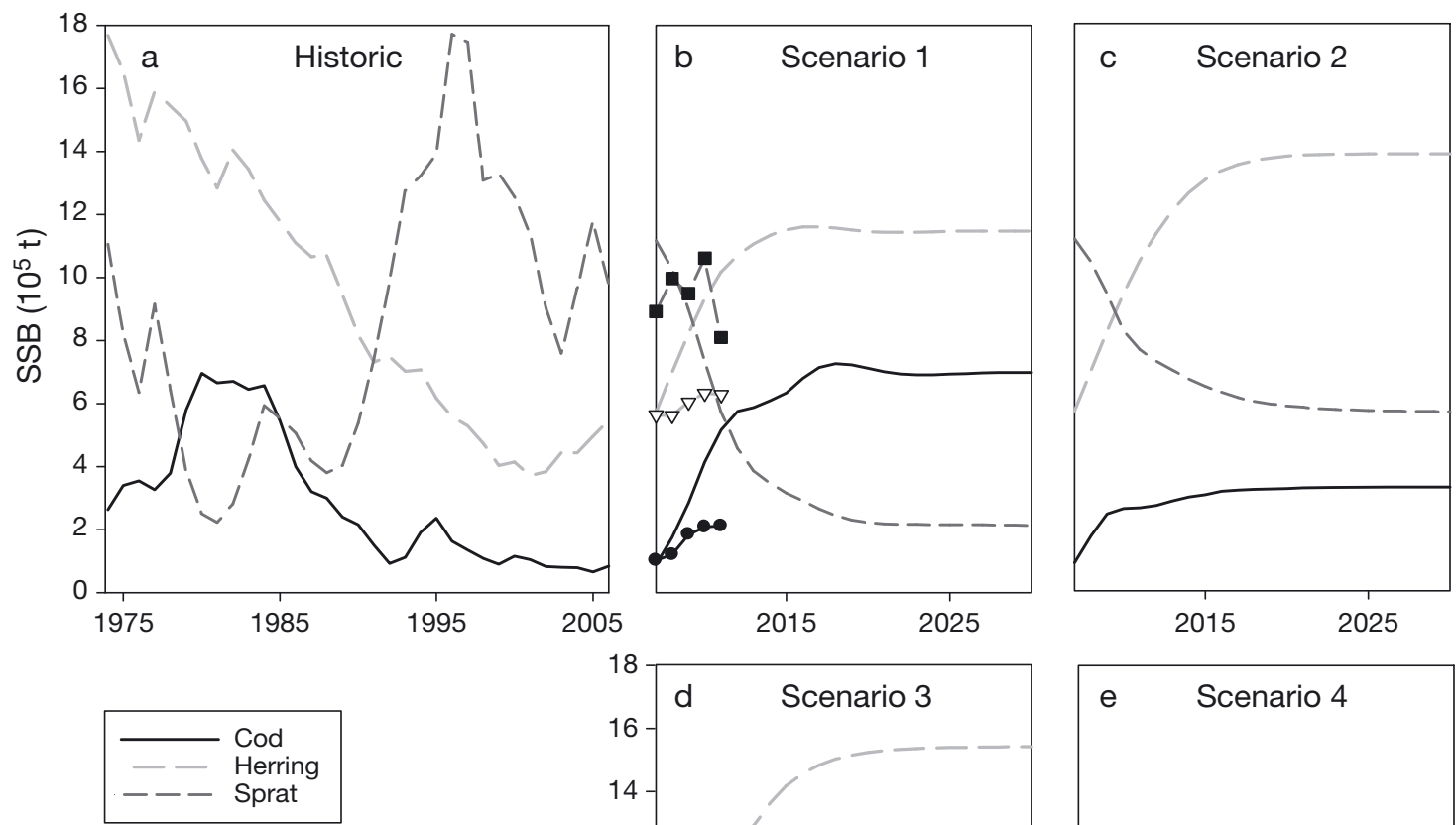

Fig. 1. Stock development of Baltic cod, herring and sprat: historic stock trends and management scenarios (see Table 1). Panel (b) includes the actual stock development from 2006 to 2011 under the cod management plan (lines with symbols)
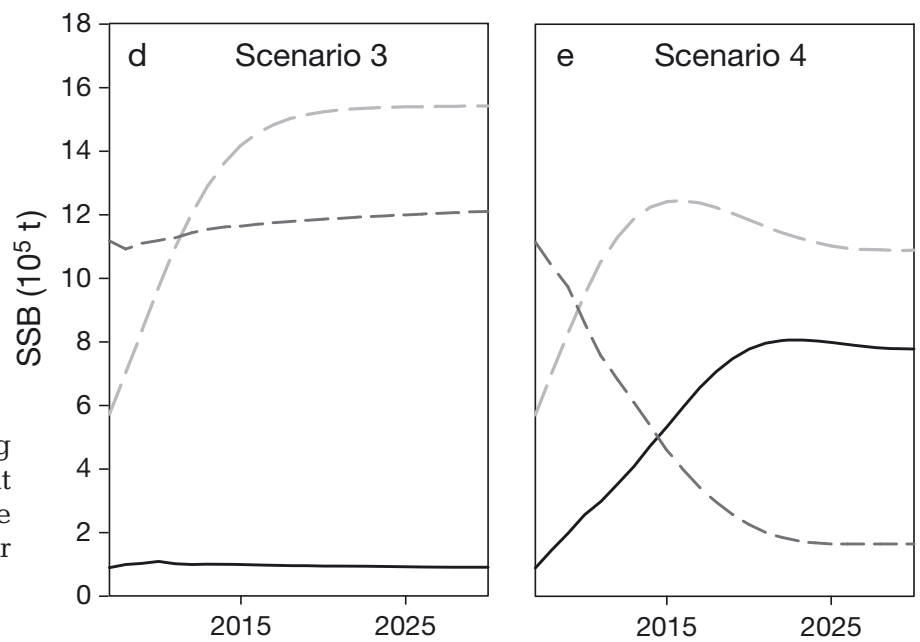
Table 6. Projected profit (million $€ \mathrm{yr}^{-1}$ ), spawning-stock biomass (1000s of t) and fishing mortality for the year 2030, for the 4 selected longterm management goals (Scenarios 1 to 4 , see Table 1). Values refer to $0 \%(5 \%)$ interest rate

\begin{tabular}{|lcccc|}
\hline Scenario & 1 & 2 & 3 & 4 \\
\hline Profit & & & & \\
Cod & $97.5(96.3)$ & $43.8(27)$ & 0 & $99.8(99.8)$ \\
Herring & $17.7(17.1)$ & $26.1(26.9)$ & $32.4(31.5)$ & $15.7(15.3)$ \\
Sprat & $2.6(2.9)$ & $8.2(9.6)$ & $15.4(15)$ & $1.8(1.8)$ \\
Sum & $117.8(116.3)$ & $78.1(63.5)$ & $47.8(46.5)$ & $117.3(116.9)$ \\
Spawning-stock biomass & & & \\
Cod & $698(689)$ & $329(264)$ & $89(89)$ & $777(777)$ \\
Herring & $1146(878)$ & $1386(1164)$ & $1540(1280)$ & $1088(805)$ \\
Sprat & $212(195)$ & $568(565)$ & $1209(965)$ & $164(130)$ \\
Fishing mortality & & & \\
Cod & $0.35(0.36)$ & $0.67(0.76)$ & $0.9(0.9)$ & $0.3(0.3)$ \\
Herring & $0.18(0.23)$ & $0.23(0.29)$ & $0.26(0.31)$ & $0.17(0.23)$ \\
Sprat & $0.45(0.58)$ & $0.59(0.74)$ & $0.49(0.66)$ & $0.4(0.51)$ \\
\hline
\end{tabular}

cod is not reduced considerably below the 2002 to 2006 level $\left(F_{2002-2006}=0.93\right)$. A reduced cod stock would, however, result in higher profits for the herring and, especially, sprat fishery.

Setting the interest rate to $5 \%$ instead of $0 \%$, as in our reference case, reduces steady-state biomasses as well as profits by maximal values of $24 \%$ (biomass) and $19 \%$ (profits). Fishing mortality is generally slightly higher. The results, however, are not qualitatively changed.

\section{Transition dynamics}

According to the economically optimal management plan (Scenario 1), the cod fishery would have been closed for almost $3 \mathrm{yr}(F=0.04$ in third year). Afterwards, a gradual increase to the steady-state value of $F=$ 0.35 , with a concurrent strong increase in profits, would have been allowed (Fig. 2). Cod stock rebuilding under the cod management plan (Scenario 4) would take a few years longer, as fishing is kept up at the reduced rate of $F=0.3$. Scenarios 2 and 3 allow for continued cod fishing at moderate (Scenario 2: sprat $B_{\mathrm{PA}}$ ) or high levels (Scenario 3: cod $B_{\mathrm{PA}}$ ). In Scenario 3 the cod fishery stays, however, unprofitable. Due to the bad stock status and the unprofitability of the cod fishery in 2006, all scenarios offer monotonically increasing total profits, even when the cod fishery is closed at the beginning.

\section{Regional distribution of profits}

In 2006, the regional distribution of profits mirrored the country-specific catch shares of herring and sprat, as the cod fishery was unprofitable, due to the severely overfished state of the cod stock in that year. The highest profits were gained in Poland and Sweden (Fig. 3a). Under the economically optimal management (Scenario 1), all countries would benefit (Fig. 3b, Table A1 in the Appendix). However, the amount of increase in benefits is very different regionally. Countries in the east, with a small share of the cod quota, e.g. Finland and Estonia, only gain a little, while countries in the west, e.g. Denmark and

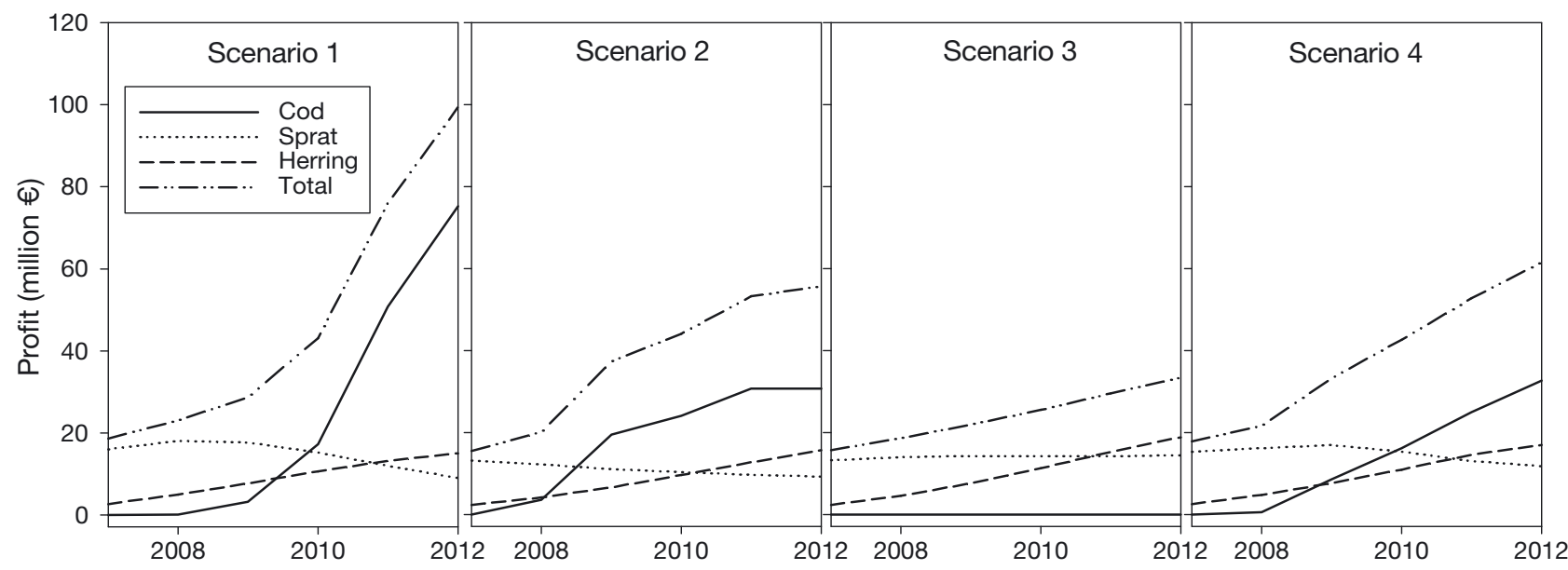

Fig. 2. Transition dynamics: path of fishery-specific, as well as total, profits (used as a performance indicator) from 2006 to 2012 for the 4 management scenarios: (1) unconstrained economic optimization, (2) optimization for profits of the cod fishery, while respecting a precautionary sprat spawning-stock biomass (SSB) (sprat $B_{\mathrm{PA}}$ ) of $570000 \mathrm{t}$, (3) optimization for profits of the sprat fishery, while respecting a precautionary $\operatorname{cod} \mathrm{SSB}\left(\operatorname{cod} B_{\mathrm{PA}}\right)$ of $88000 \mathrm{t},(4)$ simulation of the cod management plan 

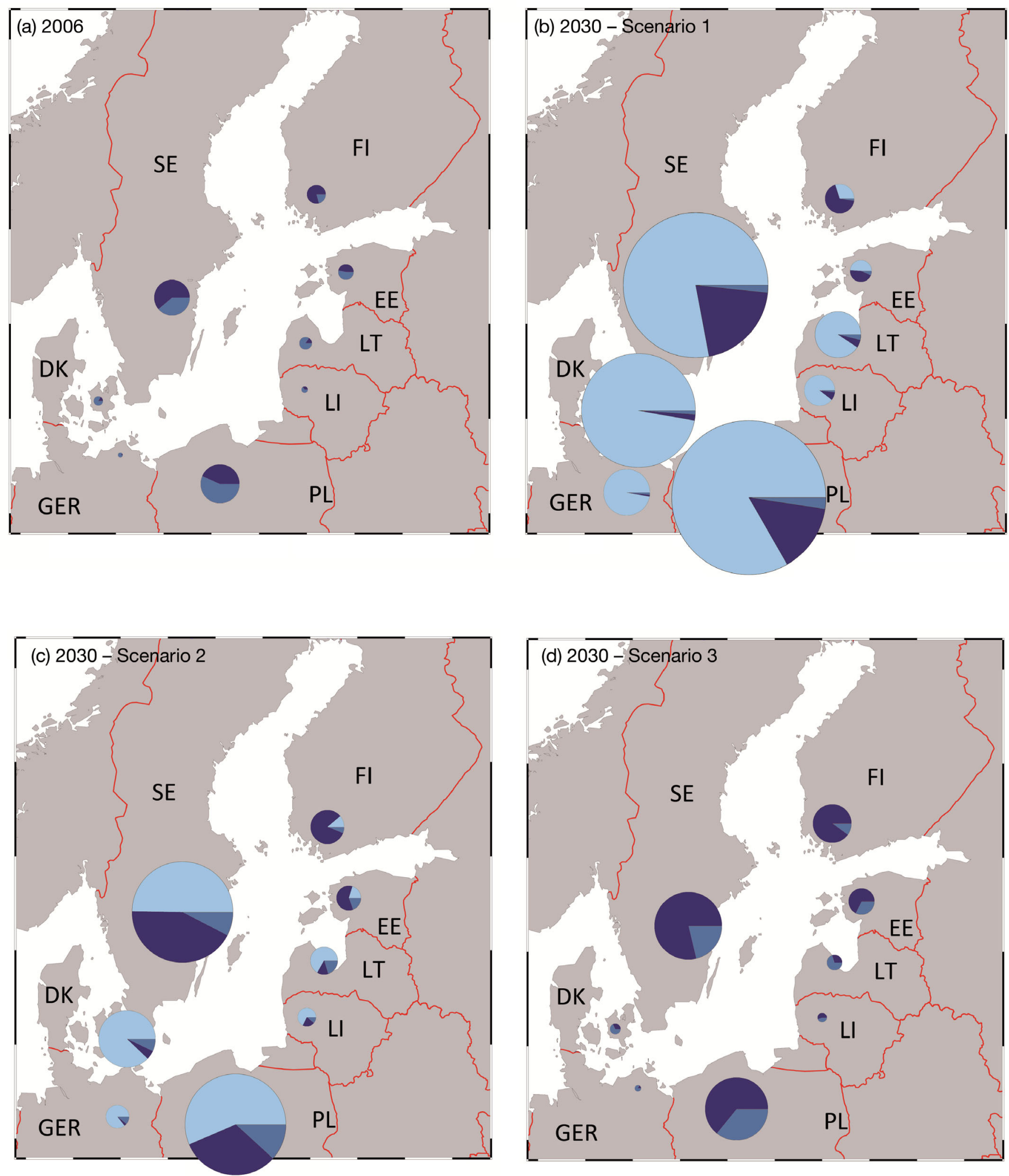

Fig. 3. Regional, country-specific distribution of profits from the cod (light shading), herring (dark shading) and sprat (medium shading) fishery; top left: situation at the beginning; remaining panels: distribution of the profits in the year 2030 according to the Scenarios. Actual values are given in Table A1 in the Appendix 
Germany, realize the highest relative increases in profits. Currently quotas cannot be traded internationally. If such an international quota trade were introduced, these results would remain the same, as the market value of quotas corresponds to the (potential) profits that can be gained in the respective fishery.

Scenarios 2 and 3 respect ecological precautionary points and can be seen to set the boundaries for feasible management options (Fig. 3c,d). Within these constraints most countries realize the highest profits under the sprat $B_{\mathrm{PA}}$ scenario (Scenario 2); some other countries, however, would benefit more from a cod $B_{\mathrm{PA}}$ scenario (i.e. Estonia and Finland).

The different management options do not only cause an uneven regional profit increase, but they also imply social consequences within a certain country, as a re-distribution of profits between the different fisheries occurs (Table A1), e.g. Scenarios 1 (economically optimal management) and 4 (cod management plan) create high total profits; the sprat fishery, however, loses substantially.

\section{DISCUSSION}

We have shown that, in a multi-species set-up, different strategic management goals will result in regionally unequal distributions of future profits. Rebuilding a large predator (cod) stock will penalize countries holding the larger shares of forage-fish fishing rights. Unconstrained economic optimization would lead to a sprat stock size below commonly accepted ecological reference levels. Even when respecting precautionary stock size limits, there are many strategic management goals from which to choose. The inflexible system of distribution of catches according to the principle of relative stability in combination with species interactions might require new measures of compensation, to secure future acceptance and compliance by all states - no matter which strategic goal is chosen.

According to the relative stability principle, the Baltic countries hold fixed shares of cod, herring and sprat quota. Therefore, the absolute catch amounts may differ between years depending on the stock status, but not the percentage distribution of TACs to countries. All Baltic countries are involved in all 3 fisheries, however, with highly variable distributional shares to species. Poland holds the largest share of the cod $(26.5 \%)$ as well as the sprat quota $(29.4 \%)$. Sweden owns the largest share of the herring quota $(33.4 \%)$. The sum of allowable catches over all 3 spe- cies in 2006 (the start of our simulation) differed between $\sim 164000 \mathrm{t}$ (Poland) and $\sim 27000 \mathrm{t}$ (Lithuania). The composition of each country's catch portfolio should determine its interest in (or opposition to) the future multi-species management goals, in particular to change from a clupeid-dominated system back to a cod-dominated system (Möllmann et al. 2009).

Stock assessment in the Baltic Sea is regularly performed by the Baltic Fisheries Assessment Working Group. Its work is currently somewhere between single-species and multi-species assessment, as natural mortality of the clupeid stocks is calculated depending on the size of the cod stock, but the group does not explicitly provide multi-species advice (ICES 2012). In early 2013, a real multi-species assessment was provided for the first time by the Benchmark Workshop on Baltic Multi-Species Assessment (WKBALT) (ICES 2013), highlighting the ecological management trade-off. Species interaction, i.e. cod predation on clupeid species, is generally of high importance in stock forecast scenarios (Kellner et al. 2011). In such an environment, single-species projections (e.g. Froese \& Proelss 2010) might be too optimistic, or even misleading. Even in the multispecies literature, economic aspects of management, especially regional distribution of profits, are rarely considered, and were not explicitly addressed in the work of the WKBALT as they were not part of the terms of reference. As shown here, such economic considerations might be as critical as ecological constraints, as they will ultimately have an influence on agreements and compliance with future management decisions.

Stock rebuilding plans can produce trade-offs due to species interactions (Gröger et al. 2007), which have to be communicated to stakeholders. Standard management trade-offs include trade-offs between harvest and spawner abundance (Collie et al. 2012), stock biomass and net financial returns (Little et al. 2011), or species conservation and size of marine protected areas (McClanahan 2011). From a more integrated point of view, trade-offs between restoration goals might be of interest (North et al. 2010), with the aim to predict benefits and quantify the associated costs. One of the few existing studies that take into account the economic impact of species interaction is on Pacific sardine Sardinops sagax (Hannesson et al. 2009). Contrary to our study, Hannesson et al. (2009) do not use an age-structured framework, and, therefore, their results cannot be directly translated into an ICES stock assessment. In the Baltic Sea, management that prioritizes profits will result in rel- 
ative winners (cod fishery), but also in relative losers (sprat fishery). The system's dynamics are mainly driven by the cod stock: The range of optimal fishing mortality $(F)$ for herring, sprat and cod is relatively narrow between scenarios (herring: 0.17 to 0.26 ; sprat: 0.4 to 0.59 ), but for cod optimal $F$ ranges from 0.3 to 0.9 in steady state. In the model, the economically profitable cod stock is rapidly built up to a SSB of $\sim 700000 \mathrm{t}$. In reality stock rebuilding is largely dependent on recruitment success. Under unfavorable environmental conditions stock rebuilding might take longer. A high cod stock causes increased predation on sprat and herring, thus leaving less scope for improved catches from the clupeid fisheries. Cod stock recovery in the optimization model is faster than has been observed in reality after adoption of the management plan, i.e. from 2006 to 2011. This is due to a sharp reduction in catches from the cod fishery for $3 \mathrm{yr}$ in the economically optimal solution, which was not conducted in reality. Instead, the management plan aims at smoothing variations by including maximum year-to-year variations of $15 \%$ (EC 2007). The steady-state biomass of cod is lower in the economically optimal solution than in the simulation of the cod management plan. Accordingly, a consequent realization of the long-term management plan for cod might lead to sprat stock sizes falling below ecological reference points, and might therefore need to be revised under multispecies- or even ecosystem-based (Pikitch et al. 2004) management.

Our model framework has room for improvements, in particular regarding environmental influences on recruitment (Köster et al. 2009), density-dependent growth (Casini et al. 2011, Gårdmark et al. 2013) and processes accounting for changes in the spatiotemporal overlap of cod and sprat (Eero et al. 2012). Nevertheless, we are confident in the range of simulated outcomes. Although future developments will most certainly increase the quantitative precision of simulations, the qualitative implications for management will likely remain robust. The Baltic Sea represents a suitable case study for demonstrating the principles of trade-off evaluation in multi-species fisheries. We are confident that our approach is readily transferrable to more complex systems, since reliable coupled ecological-economic models are increasingly becoming available.

Including ecosystem considerations other than commercially exploited species and quantifying the potential economic impacts might require valuing of, e.g., endangered species (Wallmo \& Lew 2011). Taking all ecosystem and economic feedbacks into account might also reveal unforeseen trade-offs and externalities, like in the case of French Guiana, where the (economically sub-optimal) oversized trawl fishery for shrimps positively impacts endangered frigatebirds Fregata spp. (Martinet \& Blanchard 2009). In the case of the Baltic Sea, we envisage a broadening of the scope of future work to an ecosystem level. This can be achieved by coupling to ecosystem models, in the sense of ensemble modeling as recently advocated by the Working Group on Integrated Assessments in the Baltic (Gårdmark et al. 2013).

Successful management in the future will require stakeholders to explicitly define commonly accepted fishery objectives against which trade-offs can be evaluated (Pilling et al. 2008). If quotas for the 3 species are not equally distributed among countries (like in the Baltic), new compensation schemes may be required to come to international agreements - ultimately the principle of relative stability may need to be abandoned. Additional pressure to revise the relative stability principle might also arise from the interaction of economic dynamics of fishing fleets and the European Community's legal framework, e.g. the right of establishment or free movement of workers (Morin 2000).

When performing model runs over periods of decades, it might become important to include climate change aspects, as reproductive success of all species has been shown to strongly depend on environmental conditions (cod: Köster et al. 2005; herring: Cardinale et al. 2009; sprat: Voss et al. 2006). Our model framework offers the possibility to simulate climate change scenarios for the most important environmental factors, and significantly different results may be obtained when comparing climate change to non-climate change scenarios (Voss et al. 2011). Besides the modeling of biological interaction and variability in physical forcing factors, assumptions on economic variables like cost functions, interest rates and prize elasticity also have a strong impact on the results (Voss et al. 2011, Tahvonen et al. 2013). Therefore, our data emphasize the need to proceed to inter-disciplinary multi-species management.

Acknowledgements. This study was carried out with financial support from the Cluster of Excellence 'The Future Ocean' of Kiel University. The research leading to these results also received funding from the European Community's Seventh Framework Programme (FP7/2007-2013) under grant agreement No. 289257 (MYFISH). This article does not necessarily reflect the views of the European Commission. Maps were produced using Ocean Data View software. 


\section{LITERATURE CITED}

Beverton RJH, Holt SJ (1957) The dynamics of exploited fish populations. Chapman and Hall, London

- Cardinale M, Möllmann C, Bartolino V, Casini M and others (2009) Effect of environmental variability and spawner characteristics on the recruitment of Baltic herring Clupea harengus populations. Mar Ecol Prog Ser 388:221-234

Casini M, Kornilovs G, Cardinale M, Möllmann C and others (2011) Spatial and temporal density dependence regulates the condition of central Baltic Sea clupeids: compelling evidence using an extensive international acoustic survey. Popul Ecol 53:511-523

Collie JS, Gislason H (2001) Biological reference points for fish stocks in a multispecies context. Can J Fish Aquat Sci 58:2167-2176

Collie JS, Peterman RM, Zuehlke BM (2012) A fisheries risk-assessment framework to evaluate trade-offs among management options in the presence of time-varying productivity. Can J Fish Aquat Sci 69:209-223

EC (European Community) (1999) Council Regulation (EC) No. 104/2000 on the common organization of the markets in fishery and aquaculture products

EC (2007) Council Regulation (EC) No. 1098/2007 establishing a multi-annual plan for the cod stocks in the Baltic Sea and the fisheries exploiting those stocks, amending Regulation (ECC) No. 2847/93 and repealing Regulation (EC) No. 779/97

EC (2009) Commission Regulation (EU) No. 1280/2009 fixing the reference prices for certain fishery products for the 2010 fishing year

Eero M, Vinther M, Haslob H, Huwer B, Casini M, StorrPaulsen M, Köster FW (2012) Spatial management of marine resources can enhance the recovery of predators and avoid local depletion of forage fish. Conserv Lett 5:486-492

FAO (Food and Agriculture Organization) (2012) The state of the world fisheries and aquaculture (SOFIA). FAO of the United Nations, Rome

Fernandes PG, Cook RM (2013) Reversal of fish stock decline in the Northeast Atlantic. Curr Biol 23:1432-1437

> Froese R, Proelss A (2010) Rebuilding fish stocks no later than 2015: Will Europe meet the deadline? Fish Fish 11:194-202

Gårdmark A, Lindegren M, Neuenfeldt S, Blenckner T and others (2013) Biological ensemble modeling to evaluate potential futures of living marine resources. Ecol Appl 23:742-754

- Gislason H (1999) Single and multispecies reference points for Baltic fish stocks. ICES J Mar Sci 56:571-583

Gröger JP, Rountree RA, Missong M, Rätz HJ (2007) A stock rebuilding algorithm featuring risk assessment and an optimization strategy of single or multispecies fisheries. ICES J Mar Sci 64:1101-1115

Hannesson R, Herrick S Jr, Field J (2009) Ecological and economic considerations in the conservation and management of the Pacific sardine (Sardinops sagax). Can J Fish Aquat Sci 66:859-868

ICES (2012) Report of the Baltic fisheries assessment working group (WGBFAS). ICES CM 2012/ACOM:10

ICES (2013) Report of the benchmark workshop on Baltic multispecies assessments. ICES CM 2013/ACOM:43

Kellner JB, Sanchirico JN, Hastings A, Mumby PJ (2011) Optimizing for multiple species and multiple values: tradeoffs inherent in ecosystem-based fisheries management. Conserv Lett 4:21-30
Köster FW, Möllmann C (2000) Trophodynamic control by clupeid predators on recruitment success in Baltic cod? ICES J Mar Sci 57:310-323

> Köster FW, Möllmann C, Hinrichsen HH, Wieland $\mathrm{K}$ and others (2005) Baltic cod recruitment-the impact of climate variability on key processes. ICES J Mar Sci 62:1408-1425

> Köster FW, Vinther M, MacKenzie BR, Eero M (2009) Environmental effects on recruitment and implications for biological reference points of eastern Baltic cod (Gadus morhua). J Northwest Atl Fish Sci 41:205-220

Lewy P, Vinther M (2004) Modelling stochastic age-lengthstructured multi-species stock dynamics. ICES CM 2004/FF:20

Little LR, Grafton RQ, Kompas T, Smith ADM, Punt AE, Mapstone BD (2011) Complementarity of no-take marine reserves and individual transferable catch quotas for managing the line fishery of the Great Barrier Reef. Conserv Biol 25:333-340

> Martinet V, Blanchard F (2009) Fishery externalities and biodiversity: trade-offs between the viability of shrimp trawling and the conservation of frigatebirds in French Guiana. Ecol Econ 68:2960-2968

McClanahan TR (2011) Human and coral reef use interactions: from impacts to solutions? J Exp Mar Biol Ecol 408:3-10

Möllmann C, Diekmann R, Müller-Karulis B, Kornilovs G, Plikshs M, Axe P (2009) Reorganization of a large marine ecosystem due to atmospheric and anthropogenic pressure: a discontinuous regime shift in the central Baltic Sea. Glob Change Biol 15:1377-1393

Morin M (2000) The fisheries resources in the European Union. The distribution of TACs: principle of relative stability and quota-hopping. Mar Policy 24:265-273

> Nieminen E, Lindroos M, Heikinheimo O (2012) Optimal bioeconomic multispecies fisheries management: a Baltic Sea case study. Mar Resour Econ 27:115-136

> North EW, King DM, Xu J, Hood RR and others (2010) Linking optimization and ecological models in a decision support tool for oyster restoration and management. Ecol Appl 20:851-866

Pikitch EK, Santora C, Babcock EA, Bakun A and others (2004) Ecosystem-based fishery management. Science 305:346-347

Pilling GM, Kell LT, Hutton T, Bromley PJ, Tidd AN, Bolle LJ (2008) Can economic and biological management objectives be achieved by the use of MSY-based reference points? A North Sea plaice (Pleuronectes platessa) and sole (Solea solea) case study. ICES J Mar Sci 65: 1069-1080

> Quaas MF, Froese R, Herwartz H, Requate T, Schmidt JO, Voss R (2012) Fishing industry borrows from natural capital at high shadow interest rates. Ecol Econ 82:45-52

Quaas MF, Requate T, Ruckes K, Skonhoft A, Vestergaard N, Voss R (2013) Incentives for optimal management of age-structured fish populations. Resour Energy Econ 35: 113-134

Ricker WE (1954) Stock and recruitment. J Fish Res Board Can 11:559-623

Rindorf A, Schmidt JO, Bogstad B, Reeves S, Walther Y (2013) A framework for multispecies assessment and management-An ICES/NCM background document. Nordic Council of Ministers, Copenhagen

Spence AM (1974) Blue whales and applied control theory. In: Gottinger HW (ed.) System approaches and environ- 
mental problems. Vandenhoeck and Ruprecht, Göttingen, p 97-124

STECF (Scientific, Technical and Economic Committee for Fisheries) (2011) The 2011 annual economic report on the European fishing fleet, STECF-11-16. Joint Research Centre, Ispra

Tahvonen O (2009) Economics of harvesting age-structured fish populations. J Environ Econ Manag 58:281-299

Tahvonen O, Quaas MF, Schmidt JO, Voss R (2013) Effects of species interaction on optimal harvesting of an agestructured schooling fishery. Environ Resour Econ 54:21-39
Voss R, Clemmesen C, Baumann H, Hinrichsen HH (2006) Baltic sprat larvae: coupling food availability, larval condition and survival. Mar Ecol Prog Ser 308:243-254

- Voss R, Hinrichsen HH, Quaas M, Schmidt JO, Tahvonen O (2011) Temperature change and Baltic sprat: from observations to ecological-economic modelling. ICES J Mar Sci 68:1244-1256

Wallmo K, Lew DK (2011) Valuing improvements to threatened and endangered marine species: an application of stated preference choice experiments. J Environ Manag 92:1793-1801

\section{Appendix}

Table A1. Gadus morhua, Clupea harengus, Sprattus sprattus. Country- and fishery-specific profits (million $\left.€ \mathrm{yr}^{-1}\right)$ in the year 2006 (base year), as well as in year 2030, for the 4 selected long-term management goals (see Table 1). Values refer to $0 \%$ interest rate

\begin{tabular}{|c|c|c|c|c|c|c|c|c|}
\hline & Finland & Sweden & Denmark & Germany & Poland & Estonia & Latvia & Lithuania \\
\hline \multicolumn{9}{|c|}{ 2006, base } \\
\hline Cod & 0 & 0 & 0 & 0 & 0 & 0 & 0 & 0 \\
\hline Herring & 2.9 & 4.4 & 0.3 & 0.1 & 3.3 & 1.5 & 0.4 & 0.4 \\
\hline Sprat & 0.8 & 2.8 & 1.5 & 0.9 & 4.3 & 1.7 & 2 & 0.7 \\
\hline Total & 3.7 & 7.2 & 1.7 & 1 & 7.6 & 3.2 & 2.4 & 1.1 \\
\hline \multicolumn{9}{|c|}{ Scenario 1, econ. opt. } \\
\hline Cod & 1.7 & 22.7 & 22.4 & 8.9 & 25.8 & 2.2 & 8.3 & 5.5 \\
\hline Herring & 3.9 & 5.9 & 0.4 & 0.1 & 4.4 & 2 & 0.5 & 0.5 \\
\hline Sprat & 0.1 & 0.5 & 0.3 & 0.2 & 0.8 & 0.3 & 0.4 & 0.1 \\
\hline Total & 5.7 & 29.1 & 23 & 9.2 & 31 & 4.5 & 9.2 & 6.1 \\
\hline Change & 1.5 & 4 & 13.5 & 9.2 & 4.1 & 1.4 & 3.8 & 5.6 \\
\hline \multicolumn{9}{|c|}{ Scenario 2 , sprat $B_{\mathrm{PA}}$} \\
\hline Cod & 0.8 & 10.2 & 10.1 & 4 & 11.6 & 1 & 3.7 & 2.5 \\
\hline Herring & 5.7 & 8.7 & 0.6 & 0.2 & 6.5 & 2.9 & 0.7 & 0.8 \\
\hline Sprat & 0.4 & 1.6 & 0.8 & 0.5 & 2.4 & 0.9 & 1.1 & 0.4 \\
\hline Total & 6.9 & 20.5 & 11.4 & 4.7 & 20.5 & 4.9 & 5.6 & 3.6 \\
\hline Change & 1.9 & 2.8 & 6.7 & 4.7 & 2.7 & 1.5 & 2.3 & 3.3 \\
\hline \multicolumn{9}{|c|}{ Scenario 3, $\operatorname{cod} B_{\mathrm{PA}}$} \\
\hline Cod & 0 & 0 & 0 & 0 & 0 & 0 & 0 & 0 \\
\hline Herring & 7.1 & 10.8 & 0.7 & 0.2 & 8.1 & 3.6 & 0.9 & 0.9 \\
\hline Sprat & 0.8 & 2.9 & 1.5 & 1 & 4.5 & 1.8 & 2.1 & 0.8 \\
\hline Total & 7.9 & 13.8 & 2.2 & 1.1 & 12.6 & 5.4 & 3 & 1.7 \\
\hline Change & 2.1 & 1.9 & 1.3 & 1.1 & 1.7 & 1.7 & 1.3 & 1.5 \\
\hline \multicolumn{9}{|c|}{ Scenario 4, cod mgmt } \\
\hline Cod & 1.7 & 23.2 & 22.9 & 9.1 & 26.4 & 2.2 & 8.5 & 5.6 \\
\hline Herring & 3.4 & 5.3 & 0.3 & 0.1 & 3.9 & 1.8 & 0.4 & 0.5 \\
\hline Sprat & 0.1 & 0.4 & 0.2 & 0.1 & 0.5 & 0.2 & 0.3 & 0.1 \\
\hline Total & 5.3 & 28.8 & 23.5 & 9.3 & 30.9 & 4.2 & 9.2 & 6.2 \\
\hline Change & 1.4 & 4 & 13.8 & 9.3 & 4.1 & 1.3 & 3.8 & 5.6 \\
\hline
\end{tabular}

Editorial responsibility: Jake Rice, Ottawa, Ontario, Canada
Submitted: March 10, 2013; Accepted: November 5, 2013

Proofs received from author(s): January 21, 2014 